\title{
Atividade antifúngica do extrato de Psidium guajava Linn. (goiabeira) sobre leveduras do gênero Candida da cavidade oral: uma avaliação in vitro
}

\author{
Pollianna M. Alves ${ }^{1 *}$, Pedro H.A.S. Leite ${ }^{2}$,Jozinete V. Pereira ${ }^{2}$,Luciana F. Pereira ${ }^{3}$, Maria S. \\ V. Pereira ${ }^{3}$, Jane S. Higino ${ }^{4}$ Edeltrudes O. Lima ${ }^{5}$ \\ ${ }^{1}$ Programa de Pós-graduação em Odontologia da UFPB, Universidade Federal da Paraíba, Campus I, Cidade \\ universitária, 58051-900, João Pessoa, PB, Brasil, \\ ${ }^{2}$ Departamento de Odontologia da UEPB, Universidade Estadual da Paraíba, Campus Universitário de Bodocongó, \\ 58109-753, Campina Grande, PB, Brasil, \\ ${ }^{3}$ Departamento de Biologia Molecular, Universidade Federal da Paraíba, Campus I, Cidade Universitária, \\ 58059-900, João Pessoa, PB, Brasil, \\ ${ }^{4}$ Departamento de Farmácia, Universidade Federal de Pernambuco, Av. Arthur de Sá s/n, Cidade Universitária, \\ 50740-521, Recife, PE, Brasil, \\ ${ }^{5}$ Departamento de Ciências Farmacêuticas, Universidade Federal da Paraíba, Campus I, Castelo Branco, 58051 - \\ 900, João Pessoa, PB, Brasil
}

\begin{abstract}
RESUMO: O presente estudo teve como objetivo avaliar a atividade antifúngica do extrato da folha de Psidium guajava Linn. sobre leveduras do gênero Candida, isoladas da cavidade oral, incluindo Candida albicans, C. tropicalis, C. stelatoidea e C. krusei, em análise comparativa com o gluconato de clorexidina à $0,12 \%$. Os ensaios antifúngicos foram realizados pelas técnicas de difusão em meio sólido para a determinação da Concentração Inibitória Mínima (CIM). A CIM do extrato de Psidium guajava sobre C. albicans e C. tropicalis foi de 1:32, C. stelatoidea e $C$. krusei de 1:2, formando, em média, halos de inibição entre 11 e $22 \mathrm{~mm}$. Diante dos resultados, concluí-se que o extrato da folha de Psidium guajava (goiabeira) apresenta a capacidade de inibir o crescimento de leveduras do gênero Candida da cavidade oral, o que sugere a possibilidade de utilização deste extrato como meio alternativo no tratamento das candidose orais.
\end{abstract}

Unitermos: Psidium guajava, Candida, atividade antifúngica.

\begin{abstract}
Antifungal activity of the extract of Psidium guajava Linn. ("goiabeira") upon leavens of Candida of the oral cavity: an in vitro evaluation”. The present study evaluated the antifungal in vitro activity of the extract of the leaf of Psidium guajava Linn. against leavens of Candida of the oral cavity, including Candida albicans, C. tropicalis, C. stelatoidea and C. krusei, in comparative study with chlorhexidine $(0,12 \%)$. The tests were carried out by agar-diffusion technique in dishes to determine the Minimum Inhibitory Concentration (MIC). The MIC of the extract of Psidium guajava upon C. albicans and $C$.tropicalis was 1:32, C. stelatoidea and $C$. Krusei was 1:2, making, in average, inhibition halos between 11 and $22 \mathrm{~mm}$. It can be concluded that the extract of Psidium guajava show potential to inhibit the growth of leavens of Candida of the oral cavity, it supports the possibility of the use of this extract as an alternative way in the oral candidosis treatment.
\end{abstract}

Keywords: Psidium guajava, Candida, antifungal activity.

\section{INTRODUÇ̃̃̃O}

A Candidose oral é uma infecção causada pela levedura do gênero Candida, a qual vive comumente na boca de indivíduos aparentemente sadios. A Candida é um microrganismo saprófito, que, na dependência de fatores predisponentes, que alteram a integridade orgânica, modificam a sua conformação leveduriforme para uma forma fusiforme, tornando-se patogênico (Amato Neto, 1995; Ramos et al., 1999).

$\mathrm{Na}$ microbiota normal da boca a Candida albicans é o comensal evidenciado com maior frequência atingindo até $70 \%$ do total de isolamentos (Jorge et al., 1997; Nery et al., 1994). Esta levedura tem um papel relevante no desencadeamento de infecções bucais, porém espécies consideradas patogênicas como $C$. kefir, $C$. krusei, C. tropicalis, C. stelatoidea, entre outras têm sido detectadas em casos de candidose bucal, principalmente naqueles relacionados a imunossupressão (Anaissie, 1992; Challacombe, 1994; Lima et al., 1994; Lynch, 1994).

Segundo Greenspan (1994), 41\% dos pacientes com AIDS apresentaram candidose no estágio inicial da doença, outros autores como, Ramos et al. (1999) 
verificaram a presença da candidose em $70 \%$ sendo não só um importante indicador de comprometimento imunológico, mas também, a complicação micótica mais comum entre os HIV-positivos, podendo preceder o aparecimento da candidose esofágica e do trato gastrintestinal.

Em relação ao tratamento da candidose, vários agentes antifúngicos de uso tópico e sistêmico são utilizados de acordo com o quadro clínico e estado geral do paciente (Martins; Lacaz, 1980; Cury et al., 1977). A clorexidina é amplamente empregada através de bochechos, géis e pastilhas (Fowler; Jones, 1992). Candido et al. (1996) demonstraram in vitro a atividade antifúngica do Cepacol, da Malvona e do Periogard, e observaram que a clorexidina foi a substância mais eficaz, a qual inibiu todas as cepas de Candida albicans analisadas. Pedroso et al. (2004) acrescentaram que a atividade antifúngica da clorexidina frente a Candida albicans é concentração dependente.

No entanto, devido a ocorrência de fatores indesejáveis como o surgimento de resistência de algumas cepas aos antifúngicos convencionais, principalmente em indivíduos imunodeprimidos, e, em caráter geral, a presença de efeitos tóxicos destes (Crissey et al., 1995), o estudo de plantas com propriedades terapêuticas, abrangendo aquelas com atividade antimicrobiana tem crescido bastante, não apenas por constituir-se em recurso terapêutico alternativo, mas ainda devido às perspectivas de isolar substâncias que apresentem eficácia significativa e menor índice de desvantagens (Recio et al., 1989). Um número satisfatório de produtos vegetais da região nordeste exibe substâncias com atividade antifúngica sobre leveduras de Candida, podendo atuar seletivamente sobre estes microrganismos (Minami; Oliveira, 1986; Michelin et al., 2005).

Queiroz (1998) demonstrou que os extratos do Anacardium occidentale, Plectranthus amboinicus, Punica granatum e Pithecellobium avaremotemo e o óleo essencial da Lippia sidoides revelaram boa atividade antifúngica ante 14 cepas de leveduras do gênero Candida. Santos et al. (2002) avaliaram o efeito do extrato etanólico de própolis sobre o crescimento in vitro de Candida albicans coletada de pacientes brasileiros HIV positivos e HIV - negativos portadores de candidose oral, e observaram que a própolis também tem alta eficácia na inibição desta levedura.

Os testes de sensibilidade in vitro, para fungos, não têm sido empregados rotineiramente, contudo, eles são de grande importância para a verificação de resistência destes microrganismos, para o controle da terapêutica antimicótica e para pesquisa de novas substâncias alternativas para o tratamento, como por exemplo, a utilização de extratos vegetais. (Cury et al., 1989; Souza et al., 1990; Oliveira et al., 2006).

A planta Pisidium guajava, conhecida popularmente como goiabeira, se apresenta na natureza em forma de arbusto perene da família das Mirtáceas. É uma árvore frutífera, originária das Américas Central e do Sul, cultivada em todos os países de clima tropical. Na medicina popular é utilizada para cólicas, colite, diarréia, disenteria e dor de barriga (Vendruscolo et al., 2005; Tôrres et al., 2005) Suas folhas apresentam a seguinte composição química: taninos (9-10\%), óleo essencial $(90,3 \%)$ rico em cariofileno, nerolidiol, $\beta$-bisaboleno, aromadendreno, p-selinemo, $\alpha$-pinemo e 1,8-cineol; triterpenóides (ácido oleanólico, ursólico, catecólico,

Tabela 1. Concentração Inibitória Mínima (CIM) do extrato da folha da Psidium guajava sobre as leveduras de Candida albicans, Candida tropicalis, Candida stelatoidea e Candida krusei.

\begin{tabular}{|c|c|c|c|c|c|c|}
\hline \multirow[t]{2}{*}{ Espécies fúngicas } & \multicolumn{6}{|c|}{$\begin{array}{l}\text { Diâmetro dos halos de inibição }(\mathrm{mm}) \\
\text { Concentração do extrato }(\mathrm{mg} / \mathrm{mL})\end{array}$} \\
\hline & EP & $1: 2$ & $1: 4$ & $1: 8$ & $1: 16$ & $1: 32$ \\
\hline C. albicans & 22 & 20 & 18 & 16 & 12 & 11 \\
\hline C. tropicalis & 21 & 20 & 19 & 16 & 15 & 12 \\
\hline C. stelatoidea & 13 & 12 & 0 & 0 & 0 & 0 \\
\hline C. krusei & 14 & 12 & 0 & 0 & 0 & 0 \\
\hline
\end{tabular}

$\mathrm{EP}=$ Extrato Puro

Tabela 2. Concentração Inibitória Mínima (CIM) do gluconato de clorexidina à $0,12 \%$ sobre as leveduras de Candida albicans Candida tropicalis, Candida stelatoidea e Candida krusei.

\begin{tabular}{|c|c|c|c|c|c|c|}
\hline \multirow[t]{2}{*}{ Espécies fúngicas } & \multicolumn{6}{|c|}{$\begin{array}{l}\text { Diâmetro dos halos de inibição }(\mathrm{mm}) \\
\text { Concentração do extrato }(\mathrm{mg} / \mathrm{mL})\end{array}$} \\
\hline & SD & $1: 2$ & $1: 4$ & $1: 8$ & $1: 16$ & $1: 32$ \\
\hline C. albicans & 17 & 15 & 14 & 12 & 11 & 0 \\
\hline C. tropicalis & 17 & 16 & 14 & 13 & 12 & 0 \\
\hline C. stelatoidea & 22 & 20 & 18 & 15 & 13 & 0 \\
\hline C. krusei & 21 & 18 & 15 & 14 & 0 & 0 \\
\hline
\end{tabular}

$\mathrm{SD}=$ Sem Diluição 
guaiavólico, maslínico), $\beta$-sitosterol. O caule possui taninos numa concentração de 12 a $30 \%$ (Alonso, 1998). Sato et al. (2000), pesquisando a atividade antifúngica de extratos de plantas para assepsia e esterilização, encontraram atividade antimicótica de Psidium guajava frente a Aspergillus fumigatus M008. Pessini et al. (2003) analisaram 13 extratos de diferentes plantas utilizadas na medicina popular brasileira e verificaram que a espécie Psidium guajava foi uma das mais ativas frente às leveduras $C$. albicans, $C$. krusei, $C$. parapsilosis e $C$. tropicalis.

Tendo em vista a elevada frequência e importância clínica atribuída às candidoses orais e considerando a relevância de se verificar a eficácia de meios terapêuticos alternativos, através das plantas medicinais encontradas na nossa região, partindo do conhecimento popular, consideramos ser de grande importância avaliar in vitro a atividade antifúngica, através da determinação da Concentração Inibitória Mínima (CIM) do extrato da folha da Psidium guajava Linn. (goiabeira), em estudo comparativo com o gluconato de clorexidina à $0,12 \%$, sobre leveduras de Candida albicans, C. krusei, C. tropicalis e C. stelatoidea.

\section{MATERIAL E MÉTODOS}

\section{Local do estudo}

A pesquisa experimental foi realizada no Laboratório de Genética de Microrganismos do Departamento de Biologia Molecular do Centro de Ciências Exatas e da Natureza (CCEN) da Universidade Federal da Paraíba.

\section{Material botânico e obtenção da matéria prima}

Foi estudada a folha da goiabeira (Psidium guajava Linn.). O material botânico foi obtido no mercado público central de João Pessoa - PB, e identificado botanicamente no Laboratório de Toxicologia do Departamento de Ciências Farmacêuticas da UFPE (Universidade Federal de Pernambuco - Recife). As folhas foram lavadas com água e posteriormente separadas as matérias-primas a serem utilizadas na pesquisa. Em seguida a matériaprima foi levada à secagem em estufa a $33{ }^{\circ} \mathrm{C}$, durante uma semana, para eliminação de umidade e estabilização do conteúdo enzimático. Passado este período a matériaprima foi retirada da estufa, triturada a pó em moinho elétrico e então submetida a processo de extração dos princípios ativos.

\section{Extração dos marcadores químicos}

O método de extração empregado foi a lixiviação ou percolação em fluxo contínuo à temperatura ambiente. Por se tratar de uma matéria rica em polifénois de fácil modificação estrutural, não foi utilizada a extração à quente, preservando assim a estabilidade do material. $\mathrm{Na}$ lixiviação em fluxo contínuo utilizou-se um processo onde existe a renovação constante da solução extratora (solução hidroalcoólica a $80 \% \mathrm{v} / \mathrm{v}$ ) durante um período de 24 horas. Decorrido este tempo o marco fica completamente esgotado (extração total dos marcadores ou princípios ativos). Nesta etapa, foram utilizados aproximadamente 8 litros de solução hidroalcoólica para $1 \mathrm{~kg}$ de matéria prima seca e pulverizada, visando o completo esgotamento da droga. Recuperou-se um volume de aproximadamente $6.600 \mathrm{~mL}$ de cada extrato, que após filtração para retirada das impurezas foram acondicionados em frascos âmbar, limpos, secos e estocados em câmara fria.

\section{Concentração da solução extrativa (lixiviado)}

A etapa seguinte foi a concentração da solução em nível de extrato fluido $1: 1(\mathrm{p} / \mathrm{v})$. O procedimento para a concentração do extrato foi realizado em rota-vapor (Modelo Ika-Werk) a uma temperatura constante de $45^{\circ}$, por motivo anteriormente descrito. $\mathrm{O}$ extrato obtido apresentou um pH ligeiramente ácido, em torno de 4,7.

Os procedimentos de extração e concentração dos extratos hidroalcoólicos foram realizados no Laboratório de Tecnologia Farmacêutica (LTF) da Universidade Federal de Pernambuco (UFPE).

\section{Espécies fúngicas}

Foram utilizadas as cepas de C. albicans (24), C. tropicalis (25), C. stelatoidea (23) e C. krusei (9), isoladas e identificadas no Laboratório de Micologia e posteriormente reativadas no Laboratório de Genética de Microrganismos, ambos lotados na Universidade Federal da Paraíba (UFPB).

\section{Determinação da atividade antifúngica}

A atividade antifúngica foi determinada pelo método de difusão em meio sólido para a determinação da Concentração Inibitória Mínima (CIM), através do método proposto por McGinnis (1980). As leveduras foram cultivadas em caldo nutritivo (ASD - Ágar Sabouraud Dextrose à $2 \%$ - DIFCO) e incubadas a 37 ${ }^{\circ} \mathrm{C}$ por 24 horas em estufa bacteriológica, obtendose um inoculo de $10^{5} \mathrm{UFC} / \mathrm{mL}$. Posteriormente, os crescimentos das leveduras foram difundidos nas placas de Petri na concentração de $10^{-1}$. Foram realizadas perfurações, de aproximadamente $6 \mathrm{~mm}$ de diâmetro, no meio de cultura (ASD - Ágar Sabouraud Dextrose à 2\% - DIFCO), depositado em placas de Petri. Nos orifícios foi colocado um volume de $50 \mu \mathrm{L}$ da solução da escala do extrato diluído, variando da diluição $1: 1$ até $1: 32$, em água estéril. As placas foram incubadas em estufa bacteriológica a $37{ }^{\circ} \mathrm{C}$ por um período de $24-72$ horas. Cada ensaio foi realizado em duplicata frente a cada cepa selecionada. O mesmo procedimento também foi 
realizado com o gluconato de clorexidina à $0,12 \%$. Foi considerada como CIM a menor concentração do extrato que inibiu completamente o crescimento microbiano.

\section{RESULTADOS E DISCUSSÃO}

Os resultados da atividade antifúngica da folha de Psidium guajava sobre C. albicans, C. tropicalis, C. stelatoidea e C. krusei mostram uma diminuição proporcional do diâmetro dos halos de inibição à medida que a concentração do extrato foi diminuída (Tabela 1).

Pode-se observar, semelhantemente, proporcionalidade entre a diminuição do diâmetro dos halos e a diminuição da concentração do extrato do gluconato de clorexidina à $0,12 \%$ (Tabela 2 ).

$\mathrm{O}$ extrato da folha da goiabeira apresentou excelentes resultados, inibindo o crescimento de todas as cepas analisadas. C. albicans e C. tropicalis foram inibidas até a concentração de 1:32. Já as leveduras C. stelatoidea e C. krusei apresentaram sensibilidade apenas nas maiores concentrações (1:2) (Tabela 1). A clorexidina, droga padrão, inibiu C. albicans, C. tropicalis e $C$. stelatoidea na concentração de $1: 16$, e $C$. krusei na concentração de 1:8 (Tabela 2).

Cárceres et al. (1991) relatam que a goiabeira apresenta atividade antimicótica, através do macerado hidroalcoólico de suas folhas contra Candida albicans, Candida krusei, Candida parapsilosis e Candida stellatoidea, fato este também comprovado neste nosso experimento in vitro, visto que, na concentração de 1:32 inibiu $50 \%$ das cepas analisadas (C. albicans e $C$. tropicalis) e na concentração de 1:2 inibiu também os outros 50\% das cepas (C. stelatoidea e C. krusei). Ou seja, a folha da goiabeira mostrou atividade em todas as cepas $(100 \%)$ estudadas. Resultados estes de grande valia, pois se sabe que $C$. albicans e $C$. tropicalis são as espécies do gênero Candida mais patogênicas da cavidade oral, estando presentes em mais de $70 \%$ dos isolamentos das infecções fúngicas desta área.

\section{CONCLUSÃO}

Diante dos resultados apresentados, podese concluir que o extrato da folha da Psidium guajava apresentou atividade antifúngica bastante satisfatória sobre as leveduras de $C$. albicans, $C$. tropicalis, $C$. stelatoidea e C. krusei. Considerando que a Psidium guajava (goiabeira) é de fácil acesso à população e o extrato é de baixo custo, a folha da goiabeira pode ser utilizada topicamente como meio alternativo no tratamento da candidose oral. Entretanto, avaliações farmacológicas mais abrangentes deverão ser desenvolvidas, considerando a dinâmica do corpo humano como um todo, assim como a existência de fatores sistêmicos na flora oral.

\section{REFERÊNCIAS}


BP, Nakamura CV 2003. Avaliação da atividade antibacteriana e antifúngica de extratos de plantas utilizados na medicina popular. Rev Bras Farmacogn 13(Supl. 1): 21-24.

Queiroz MVF 1998. Atividade antifúngica in vitro de plantas medicinais frente a leveduras do gênero Candida isoladas da cavidade bucal. João Pessoa, 98f. Dissertação de Mestrado - Programa de Pós-graduação em Odontologia, Universidade Federal da Paraíba.

Ramos INC, Vasconcelos LCS, Lima MGGC, Figueiredo RLQ 1999. Candidose Bucal em pacientes HIV-positivos. $J B C$ 3: 59-61.

Recio MC, Rios JL, Villar A 1989. A review of some anitmicrobial compounds isolated from medicinal plants reported in the literature 1978-1988. Phytother Res 3: 117-125.

Santos VR, Mesquita RA, Senna MIB, Martins RS, Pereira ES, Lima Júnior SM 2002. Efeito do extrato etanólico de própolis comercial sobre o crescimento in vitro de Candida albicans coletados de pacientes brasileiros HIV - positivos e HIV - negativos portadores de candidose bucal. Jornal do CROMG 134: 4.

Sato J, Goto K, Nanjo F, Kawai S, Murata K 2000. Antifugal activity of plant extracts against Arthrinium sacchari and Chaetomium funicola. J Biosci Bioeng 90: 442446.

Souza BEM, Paula CR, Purcho AGV, Correa B, Cury AE 1990. Aspectos morfofisiológicos, fatores de virulência e sensibilidade a antifúngicos de amostras de Candida albicans, sorotipos A e B, isoladas em São Paulo, Brasil. Rev Microbiol 21: 247-253.

Tôrres AR, Oliveira RAG, Diniz MFFM, Araújo EC 2005 Estudo sobre o uso de plantas medicinais em crianças hospitalizadas da cidade de João Pessoa: riscos e benefícios. Rev Bras Farmacogn 15: 373-380.

Vendruscolo GS, Rates SMK, Mentz LA 2005. Dados químicos e farmacológicos sobre as plantas utilizadas como medicinais pela comunidade do bairro Ponta Grossa, Porto Alegre, Rio Grande do Sul. Rev Bras Farmacogn 15: 361-372. 